\title{
Prevalence and Determinants of Human Papilloma Virus Infection and Cervical Intraepithelial Neoplasia (CIN) among Women Living with HIV/AIDS in Mumbai, India
}

\author{
Vandita Pahwa ${ }^{1}$ Sharmila A. Pimple ${ }^{1}$ Gauravi A. Mishra ${ }^{10}$ Kavita V. Anand ${ }^{1}$ \\ ${ }^{1}$ Department of Preventive Oncology, Centre for Cancer \\ Epidemiology, Tata Memorial Centre, Homi Bhabha National \\ Institute, Mumbai, Maharashtra, India \\ Ind J Med Paediatr Oncol 2022;43:97-102.

\begin{abstract}
Address for correspondence Sharmila A. Pimple, MD, PSM, Department of Preventive Oncology, Centre for Cancer Epidemiology, Tata Memorial Centre, Homi Bhabha National Institute, 3rd Floor, Service Block, E. Borges Marg, Parel, Mumbai 400 012, Maharashtra, India (e-mail: drsharmilapatil@yahoo.com; pimplesa@tmc.gov.in).
\end{abstract}

\begin{abstract}
Keywords

- cervical cancer

- CIN

- HIV

- screening

- precancer

Human immunodeficiency virus (HIV) infection among women predisposes them to human papillomavirus (HPV) infection, the causative agent for cervical cancer. The study retrospectively analyzed the data of 291 women living with HIV AIDS (Acquired immunodeficiency syndrome) to assess the prevalence and determinants of the HPV infection and cervical intraepithelial neoplasia (CIN). The study found a high prevalence of cervical HPV infection (34.4\%), CIN I (6.2\%), and CIN II+ (8.6\%). Participants with HPV DNA positivity are significantly more likely to be aged younger than 35 years (odds ratio $[O R]=1.64,95 \%$ confidence interval $[\mathrm{Cl}]=1.01-2.69)$, housewives $(\mathrm{OR}=2.29,95 \%$ $\mathrm{Cl}=1.31-3.99)$, married at $<20$ years of age $(\mathrm{OR}=2.02,95 \% \mathrm{Cl}=1.13-3.58)$, and have been pregnant more than two times $(O R=1.76,95 \% \mathrm{Cl}=1.08-2.87)$. Participants with CIN II+ are significantly more likely to be not married (OR $=3.363,95 \%$ $\mathrm{Cl}=1.302-8.686)$. Considering the high prevalence of HPV and CIN observed among HIV women, it is worthwhile to integrate cervical cancer awareness programs and screening with routine follow-up of HIV patients at antiretroviral therapy clinic. This susceptible population needs attention to reduce the burden of cervical cancer in the country.
\end{abstract}

\section{Introduction}

The human papillomavirus (HPV) is the most prevalent sexually transmitted infection. There are more than 100 types of HPVs, out of which, 14 viruses are oncogenic. Among these 14 viruses, 2 (HPV 16 and HPV 18) are responsible for $70 \%$ of cervical cancer cases. ${ }^{1}$ In most cases, the infection is asymptomatic and resolves on its own. ${ }^{2}$ However, the per- sistence of the infection may cause changes at the squamocolumnar junction of the cervical epithelium and lead to a cascade of changes that can initiate cervical intraepithelial neoplasia (CIN). ${ }^{2}$ Cervical cancer, though preventable, ranks as the fourth most commonly occurring cancer among females in the world. ${ }^{3}$ It is the second most common cancer among females in India. ${ }^{4}$ With vaccination and screening, cervical cancer can be prevented and detected at a CIN stage. ${ }^{5}$
DOI https://doi.org/ 10.1055/s-0042-1742661. ISSN 0971-5851.

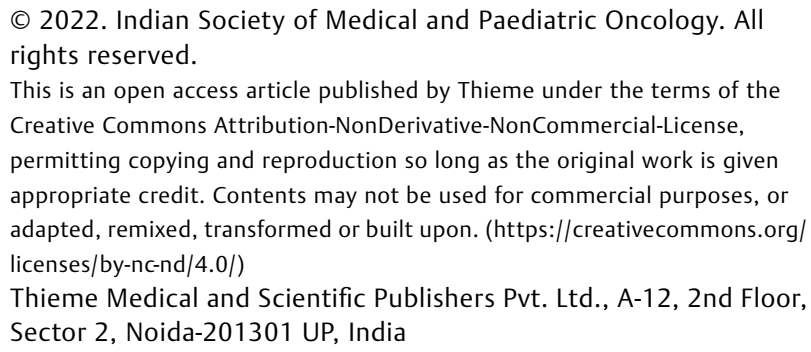

(C) 2022. Indian Society of Medical and Paediatric Oncology. All rights reserved.

This is an open access article published by Thieme under the terms of the Creative Commons Attribution-NonDerivative-NonCommercial-License, permitting copying and reproduction so long as the original work is given appropriate credit. Contents may not be used for commercial purposes, or adapted, remixed, transformed or built upon. (https://creativecommons.org/ licenses/by-nc-nd/4.0/)

Thieme Medical and Scientific Publishers Pvt. Ltd., A-12, 2nd Floor, Sector 2, Noida-201301 UP, India 
Human immunodeficiency virus (HIV)/acquired immunodeficiency syndrome (AIDS) continues to be a public health problem in India, even though the prevalence is at a decline. The prevalence reported in India was $0.22 \%(0.17-$ $0.29 \%$ ) in $2019 .{ }^{6}$ When turned into absolute numbers, the quantum becomes much bigger for a country like India which has a huge population. ${ }^{6}$ Studies have shown that HIV predisposes women to HPV infection. HIV-positive women have a two times higher rate of progression from HPV to highgrade squamous intraepithelial lesion (HSIL) than HIV-negative women. The CIN cases undergoing regression are reduced, and those going toward higher grades of the lesion are increased. ${ }^{7}$ The recent guideline by World Health Organization recommends cervical cancer screening every 3 to 5 years using HPV DNA-based tests for HIV-positive patients as compared with longer screening interval for the general population. ${ }^{8}$

Our study was thus performed to assess the prevalence and determinants of the HPV infection and CIN among women living with HIV/AIDS in Mumbai so that steps could be taken to reduce the morbidity and mortality from cervical cancer among them.

\section{Materials and Methods}

A retrospective analysis was undertaken for 291 HIV-positive women attending cervical cancer screening services from May 2010 to June 2015 in a tertiary cancer center in Mumbai. Inclusion criteria included HIV-positive women aged older than or equal to 21 years, with laboratoryproven HIV diagnosis, screened with all the three techniques: pap smear, visual inspection by acetic acid, and HPV DNA hybrid capture II test. They had also undergone the procedure of diagnostic colposcopy. Women who had not received the three screening tests and diagnostic colposcopy were excluded from the study. All the women were administered simultaneous screening with these tests followed by colposcopy and histopathology. Digital information on patient demographics, reproductive history, HIV status, cervical cancer screening tests, diagnostic colposcopy, and histopathology reports were retrieved from the hospital electronic records in structured data collection forms for audit and analysis. The original research paper on Screening for Early Detection of Cervical Cancer in Women Living with HIV in Mumbai, India - Retrospective Cohort Study from a Tertiary Cancer Center details the retrospective audit methodology. The data relating to determinants of HPV and CIN have been presented here. The outcome measures in our study included the prevalence of HPV infection and CIN II+ positivity on histopathology while studying the risk factors responsible for the presence of HPV infection and CIN II+ positivity.

\section{Ethics}

This study was performed in agreement with the Declaration of Helsinki and Good Clinical Practice as stated by the International Conference on Harmonization. As per the protocol, a unique identification code was generated for each patient, thereby protecting their confidentiality. Due to the retrospective nature of the study, a waiver for informed consent was taken from the ethics committee.

\section{Data Management and Analysis}

Data were entered and analyzed in IBM SPSS Statistics v 24.0 (SPSS/IBM, Chicago, Illinois, United States). Data were regularly checked for consistency, safety, and analysis at regular intervals. Frequencies of the sociodemographic, reproductive, and sexual behavior attributes were determined. Prevalence of HPV infection, disease spectrum of CIN, risk factors for acquiring HPV infection, and CIN with odds ratio (OR) and 95\% confidence interval (CI) were estimated.

\section{Results}

\section{Prevalence of Cervical HPV Infection and CIN}

Two hundred ninety-one HIV-positive females were enrolled for the study. The prevalence of cervical HPV infection among our participants was $34.4 \%(95 \% \mathrm{Cl}=28.9$ 40.1\%). The prevalence of CIN I and CIN II+ in the patients was $6.2 \%(95 \% \mathrm{Cl}=3.7-9.6 \%)$ and $8.6 \%(95 \% \mathrm{Cl}=5.6-12.4 \%)$, respectively.

\section{Determinants of HPV Infection among Women Living with HIV|AIDS}

The study shows that the participants with HPV DNA positivity are significantly more likely to be aged younger than 35 years $(\mathrm{OR}=1.64,95 \% \mathrm{CI}=1.01-2.69)$, housewives ( $\mathrm{OR}$ $=2.29,95 \% \mathrm{Cl}=1.31-3.99)$, married at $<20$ years of age $(\mathrm{OR}=2.02,95 \% \mathrm{CI}=1.13-3.58)$, and have been pregnant more than two times $(\mathrm{OR}=1.76,95 \% \mathrm{Cl}=1.08-2.87)$.

Participants with HPV infection were more likely to be HIV positive for $<5$ years ( $\mathrm{OR}=1.58,95 \% \mathrm{CI}=0.97-2.57$ ), on antiretroviral therapy (ART) treatment $<1$ year $(\mathrm{OR}=1.40$, $95 \% \mathrm{Cl}=0.85-2.31)$, with history of tuberculosis $(\mathrm{OR}=1.18$, $95 \% \mathrm{CI}=0.71-1.99)$, and $\mathrm{CD} 4$ cell count $<500(\mathrm{OR}=1.12,95 \%$ $\mathrm{CI}=0.54-2.33)$. However, these associations were not found to be significant ( - Table 1 ).

\section{Determinants of Cervical Intraepithelial Neoplasia among Women Living with HIV|AIDS}

The study shows that the participants with CIN II+ are significantly more likely to be currently unmarried (OR $=3.363,95 \% \mathrm{CI}=1.302-8.686)$. Nonsignificant positive associations were found between HPV occurrence and lower than primary level of education $(\mathrm{OR}=1.557,95 \% \mathrm{CI}=0.684-$ 3.546), being a housewife ( $\mathrm{OR}=2.115,95 \% \mathrm{Cl}=0.769$ 5.819), age at marriage $(\mathrm{OR}=3.211,95 \% \mathrm{CI}=0.935$ 11.031), getting pregnant more than two times ( $\mathrm{OR}=2.163$, $95 \% \mathrm{Cl}=0.923-5.069)$, tobacco use $(\mathrm{OR}=1.184,95 \% \mathrm{CI}$ $=0.452-3.105)$, duration of HIV positivity less than 5 years $(\mathrm{OR}=1.805,95 \% \mathrm{CI}=0.790-4.125)$, husband being HIV positive for more than 5 years $(\mathrm{OR}=1.394,95 \% \mathrm{CI}=0.522$ 3.724), and instances of HIV being transmitted sexually $(\mathrm{OR}=1.166,95 \% \mathrm{CI}=0.469-2.900)$ ( -Table 2). 
Table 1 Determinants of HPV infection among women living with HIV/AIDS ( $n=291)$

\begin{tabular}{|c|c|c|c|c|c|c|}
\hline Baseline characteristics & Total, $n$ (\%) & HPV present, $n$ & HPV absent, $n$ & OR & $95 \% \mathrm{Cl}$ & $p$-Value \\
\hline \multicolumn{7}{|l|}{ Age } \\
\hline$<35 y$ & $148(50.85)$ & 59 & 89 & 1.649 & \multirow[t]{2}{*}{$1.011-2.691$} & \multirow[t]{2}{*}{0.045} \\
\hline$>35 y$ & $143(49.14)$ & 41 & 102 & 1 & & \\
\hline \multicolumn{7}{|l|}{ Education } \\
\hline Primary or below & $111(38.14)$ & 42 & 69 & 1.280 & \multirow[t]{2}{*}{$0.781-2.100$} & \multirow[t]{2}{*}{0.328} \\
\hline Middle or above & $180(61.85)$ & 58 & 122 & 1 & & \\
\hline \multicolumn{7}{|l|}{ Occupation } \\
\hline Housewife & $194(66.66)$ & 78 & 116 & 2.292 & \multirow[t]{2}{*}{$1.316-3.994$} & \multirow[t]{2}{*}{0.003} \\
\hline Professional/semiskilled worker & $97(33.33)$ & 22 & 75 & 1 & & \\
\hline \multicolumn{7}{|l|}{ Marital status } \\
\hline Currently not married $^{\text {a }}$ & $148(50.85)$ & 58 & 90 & 1.550 & \multirow[t]{2}{*}{$0.951-2.525$} & \multirow[t]{2}{*}{0.079} \\
\hline Married & $143(49.14)$ & 42 & 101 & 1 & & \\
\hline \multicolumn{7}{|l|}{ Age at marriage } \\
\hline$<20 y$ & $207(71.13)$ & 80 & 127 & 2.016 & \multirow[t]{2}{*}{$1.135-3.581$} & \multirow[t]{2}{*}{0.017} \\
\hline$>20 y$ & $84(28.86)$ & 20 & 64 & 1 & & \\
\hline \multicolumn{7}{|l|}{ Pregnancies } \\
\hline$>2$ & $136(46.73)$ & 56 & 80 & 1.766 & \multirow[t]{2}{*}{$1.084-2.878$} & \multirow[t]{2}{*}{0.022} \\
\hline$<2$ & $155(53.26)$ & 44 & 111 & 1 & & \\
\hline \multicolumn{7}{|l|}{ Tobacco use } \\
\hline Yes & $62(21.30)$ & 21 & 41 & 0.973 & \multirow[t]{2}{*}{$0.538-1.759$} & \multirow[t]{2}{*}{0.927} \\
\hline No & $229(78.69)$ & 79 & 150 & 1 & & \\
\hline \multicolumn{7}{|l|}{ Husband's HIV status } \\
\hline Positive & $54(18.56)$ & 14 & 40 & 0.615 & \multirow[t]{2}{*}{$0.316-1.193$} & 0.151 \\
\hline Negative & $237(81.44)$ & 86 & 151 & 1 & & \\
\hline Husband's HIV duration $(n=264)^{b}$ & & & & & & \\
\hline$>5 y$ & $171(64.77)$ & 54 & 117 & 0.839 & $0.492-1.430$ & 0.519 \\
\hline$<5$ y or not HIV positive & $93(35.22)$ & 33 & 60 & 1 & & \\
\hline Method of HIV transmission $(n=2$ & & & & & & \\
\hline Sexual & $201(69.07)$ & 68 & 133 & 0.697 & $0.3037-1.601$ & 0.393 \\
\hline Nonsexual & $26(8.93)$ & 11 & 15 & 1 & & \\
\hline Duration of HIV-positive status & & & & & & \\
\hline$<5 y$ & $124(42.61)$ & 50 & 74 & 1.581 & $0.970-2.576$ & 0.066 \\
\hline$>5 y$ & $167(57.38)$ & 50 & 117 & 1 & & \\
\hline On ART treatment & & & & & & \\
\hline No & $75(25.77)$ & 24 & 51 & 0.867 & $0.495-1.517$ & 0.617 \\
\hline Yes & $216(74.22)$ & 140 & 76 & 1 & & \\
\hline Duration on ART treatment & & & & & & \\
\hline$<1 \mathrm{y}$ & $107(36.76)$ & 42 & 65 & 1.404 & $0.854-2.308$ & 0.181 \\
\hline$>1 \mathrm{y}$ & $184(63.23)$ & 58 & 126 & 1 & & \\
\hline CD4 + cell count (500 cutoff) ( $n=$ & & & & & & \\
\hline$<500$ & $100(69.44)$ & 39 & 61 & 1.119 & $0.537-1.998$ & 0.764 \\
\hline$>500$ & $44(30.55)$ & 16 & 28 & 1 & & \\
\hline Coinfection with tuberculosis & & & & & & \\
\hline Yes & $89(30.58)$ & 33 & 56 & 1.187 & $0.706-2.331$ & 0.518 \\
\hline No & $202(69.41)$ & 67 & 135 & 1 & & \\
\hline
\end{tabular}

Abbreviations: AIDS, acquired immunodeficiency syndrome; ART, antiretroviral therapy; $\mathrm{Cl}$, confidence interval; HIV, human immunodeficiency virus; HPV, human papillomavirus; OR, odds ratio.

${ }^{a}$ Currently not married women included single women, separated, or widowed women.

'Husband's HIV duration not known in 27 participants.

'Details regarding method of HIV transmission not known among 64 participants.

${ }^{\mathrm{d}} \mathrm{CD} 4$ counts were unavailable for 147 participants. 
Table 2 Determinants of cervical intraepithelial neoplasia among women living with HIV/AIDS $(n=291)$

\begin{tabular}{|c|c|c|c|c|c|c|}
\hline Baseline characteristics & Total, $n(\%)$ & CIN II + present, $n$ & CIN II + absent, $n$ & OR & $95 \% \mathrm{Cl}$ & $p$-Value \\
\hline \multicolumn{7}{|l|}{ Age } \\
\hline$<35 \mathrm{y}$ & $148(50.85)$ & 11 & 137 & 0.74 & \multirow[t]{2}{*}{$0.324-1.689$} & \multirow[t]{2}{*}{0.474} \\
\hline$>35 y$ & $143(49.14)$ & 14 & 129 & 1 & & \\
\hline \multicolumn{7}{|l|}{ Education } \\
\hline Primary or below & $111(38.14)$ & 12 & 99 & 1.557 & \multirow[t]{2}{*}{$0.684-3.546$} & \multirow[t]{2}{*}{0.292} \\
\hline Middle or above & $180(61.85)$ & 13 & 167 & 1 & & \\
\hline \multicolumn{7}{|l|}{ Occupation } \\
\hline Housewife & $194(66.66)$ & 20 & 174 & 2.115 & \multirow[t]{2}{*}{$0.769-5.819$} & \multirow[t]{2}{*}{0.147} \\
\hline Professional/semiskilled worker & $97(33.33)$ & 5 & 92 & 1 & & \\
\hline \multicolumn{7}{|l|}{ Marital status } \\
\hline Currently not married ${ }^{\mathrm{a}}$ & $148(50.85)$ & 19 & 129 & 3.363 & \multirow[t]{2}{*}{$1.302-8.686$} & \multirow[t]{2}{*}{0.012} \\
\hline Married & $143(49.14)$ & 6 & 137 & 1 & & \\
\hline \multicolumn{7}{|l|}{ Age at marriage } \\
\hline$<20 y$ & $207(71.13)$ & 22 & 185 & 3.211 & \multirow[t]{2}{*}{$0.935-11.031$} & \multirow[t]{2}{*}{0.064} \\
\hline$>20 y$ & $84(28.86)$ & 3 & 81 & 1 & & \\
\hline \multicolumn{7}{|l|}{ Pregnancies } \\
\hline$>2$ & $136(46.73)$ & 16 & 120 & 2.163 & \multirow[t]{2}{*}{$0.923-5.069$} & \multirow[t]{2}{*}{0.076} \\
\hline$<2$ & $155(53.26)$ & 9 & 146 & 1 & & \\
\hline \multicolumn{7}{|l|}{ Tobacco use } \\
\hline Yes & $62(21.30)$ & 6 & 56 & 1.184 & \multirow[t]{2}{*}{$0.452-3.105$} & \multirow[t]{2}{*}{0.731} \\
\hline No & $229(78.69)$ & 19 & 210 & 1 & & \\
\hline \multicolumn{7}{|l|}{ Husband's HIV status } \\
\hline Positive & $54(18.56)$ & 4 & 50 & 0.823 & \multirow[t]{2}{*}{$0.271-2.503$} & 0.731 \\
\hline Negative & $237(81.44)$ & 21 & 216 & 1 & & \\
\hline Husband's HIV duration $(n=264)^{\mathrm{b}}$ & & & & & & \\
\hline$>5 y$ & $171(64.77)$ & 15 & 156 & 1.394 & $0.522-3.724$ & 0.507 \\
\hline$<5$ y or not HIV positive & $93(35.22)$ & 6 & 87 & 1 & & \\
\hline Method of HIV transmission $(n=2$ & & & & & & \\
\hline Sexual & $201(69.07)$ & 18 & 183 & 2.459 & $0.314-19.23$ & 0.3761 \\
\hline Nonsexual & $26(8.93)$ & 1 & 25 & 1 & & \\
\hline Duration of HIV-positive status & & & & & & \\
\hline$<5 y$ & $124(42.61)$ & 14 & 110 & 1.805 & $0.790-4.125$ & 0.161 \\
\hline$>5 y$ & $167(57.38)$ & 11 & 156 & 1 & & \\
\hline On ART treatment & & & & & & \\
\hline No & $75(25.77)$ & 5 & 70 & 0.700 & $0.253-1.936$ & 0.253 \\
\hline Yes & $216(74.22)$ & 20 & 196 & 1 & & \\
\hline Duration on ART treatment & & & & & & \\
\hline$<1$ y & $107(36.76)$ & 7 & 100 & 0.646 & $0.260-1.600$ & 0.345 \\
\hline$>1 \mathrm{y}$ & $184(63.23)$ & 18 & 166 & 1 & & \\
\hline Coinfection & & & & & & \\
\hline TB & $89(30.58)$ & 7 & 82 & 0.275 & $0.035-2.179$ & 0.211 \\
\hline No TB & $202(69.41)$ & 18 & 184 & 1 & & \\
\hline CD4 + cell count (500 cutoff) $(n=$ & & & & & & \\
\hline$<500$ & $100(69.44)$ & 11 & 89 & 0.964 & $0.314-2.961$ & 0.949 \\
\hline$>500$ & $44(30.55)$ & 5 & 39 & 1 & & \\
\hline
\end{tabular}

Abbreviations: AIDS, acquired immunodeficiency syndrome; ART, antiretroviral therapy; $\mathrm{CI}$, confidence interval; CIN, cervical intraepithelial neoplasia; HIV, human immunodeficiency virus; OR, odds ratio; TB, tuberculosis.

${ }^{a}$ Currently not married women included single women, separated, or widowed women.

bHusband's HIV duration not known in 27 participants.

${ }^{\mathrm{C}}$ Details regarding method of HIV transmission not known among 64 participants.

${ }^{\mathrm{d}} \mathrm{CD} 4$ counts were unavailable for 147 participants. 


\section{Discussion}

Studies have shown that HIV is a predisposing factor for HPV infection. ${ }^{9,10}$ The chances of acquiring HIV infection are also more than twice in women with a history of HPV infection of the cervix. ${ }^{11}$ HIV decreases the immunity, thereby causing a lack of clearance of HPV infection, its persistence, and hence, causes cervical lesions. The prevalence of HPV in our study was found to be $34.4 \%$. This prevalence is higher than reported among HIV-positive women in eastern India (26.85\%) and that reported from a recent study in Africa (22.2\%). ${ }^{12,13}$ Prevalence of high-risk (HR-HPV) HPV infection similar to our study was found in Brazil (31.1\%). ${ }^{14}$ However, a study in Pune and a systematic review by Bogale et al reported a higher prevalence of 41.7 and $51.0 \%$, respectively. ${ }^{15,16}$ Analysis from studies suggests 30 to $80 \%$ of HIVpositive women suffer from HR-HPV. ${ }^{17}$

Histological lesions were present in 43 (14.7\%) participants. Among these, CIN1 and CIN2+ were present in 18 (6.2\%) and $25(8.6 \%)$ participants, respectively. Prevalence comparable to our study was noted by Chakravarty et al where HSIL and cervical cancer were noted in 5.35 and $1.6 \%$ of females, respectively. ${ }^{12}$ Daniel et al reported a slightly lower prevalence of HSIL and higher lesions in Nigeria (4.9\%). ${ }^{12,18}$ Our prevalence is lower than that reported by Sahasrabuddhe et al in Pune (27.7\%). ${ }^{15}$ The review done by Patel et al found cervical precancer and invasive cancer of the cervix in 10 to $40 \%$ and 1.3 to $1.7 \%$ of the HIV-positive women. ${ }^{17}$

As the age increases, the risk of getting HR-HPV decreases. ${ }^{9}$ In our study also, HPV DNA positivity was significantly more likely in HIV women aged younger than 35 years. The study done by Chakravarty et al showed younger women to be twice at risk for HPV infection $(\mathrm{OR}=2.56,95 \% \mathrm{CI}=1.26$ $5.19) .{ }^{12}$ Some studies, however, have shown results contrary to our findings. In the study at Togo, HPV positivity was high among women aged older than 50 years. ${ }^{13}$ The study in West Bengal showed an increased HPV prevalence till 40 years of age. ${ }^{10}$

Regarding sociodemographic factors such as literacy, our study shows a nonsignificant association between the lower level of education with HPV positivity and CIN. The study by Sahasrabuddhe et al and Chakravarty et al shows that women with education less than that of primary education level have increased CIN severity and HPV positivity, respectively. ${ }^{12,15}$ Our study shows that HIVpositive women with more than two pregnancies had twice the chances to develop CIN. Although the results in our study were nonsignificant, literature shows that multiparity increases the tendency to develop an intraepithelial lesion. ${ }^{18,19}$ Studies have shown that tobacco use is a significant predictor of intraepithelial neoplasia. In our study, although CIN II+ was more common among women who consumed tobacco, this association was nonsignificant. Similar results were seen in the study done by Daniel et al in Nigeria. ${ }^{20}$

Regarding CD4+ cell count, our analysis shows participants with HPV infection were more likely to have CD4+ cell count $<500(\mathrm{OR}=1.12,95 \% \mathrm{CI}=0.54-2.33)$. The results were not significant. The study also revealed no association between CD4+ cell count and CIN. In the same way, the study in Brazil showed nonsignificant association between low CD4+ cell count and HPV infection ( $p$-value $=0.62) .{ }^{14}$ Chakravarty et al in West Bengal $(\mathrm{OR}=2.46,95 \%$ $\mathrm{CI}=1.26-4.83$ ), and systematic review by Bogale et al presented parallel results. ${ }^{12,16}$ However, Atashili et al demonstrated CIN more likely in participants with low CD4+ cell count. ${ }^{19}$

In our study, nonsignificant association was found between HPV positivity and starting ART within 1 year (OR $=1.40,95 \% \mathrm{CI}=0.85-2.31$ ). In the study done by Sahasrabuddhe et al, increasing severity of CIN was found with patients receiving ART treatment (adjusted OR $=2.24,95 \%$ $\mathrm{CI}=[1.17-4.26]) .^{15}$ There is limited literature available on the impact of ART treatment on HPV infection and CIN. However, since life expectancy has increased with ART regimens, regular screening for cervical cancer is recommended to prevent mortality.

It has been observed that non-16 and non-18 HPV genotypes are more common among HIV-positive women. ${ }^{10}$ In the study done at Togo, the genotype 16 prevalence was found to be low. ${ }^{13}$ This may have implications on cervical cancer control using HPV vaccination programs, where these vaccines may only have a limited role to play among HIVinfected women.

Our study does suffer from a few limitations. Complete information regarding husband's HIV infection duration, details regarding the method of HIV transmission, and CD4 counts were unavailable for some participants. Details regarding sexual activity and tobacco intake were selfreported. Participants would have refrained from giving true responses to these questions due to their personal inhibitions and cultural barriers which could have led them under reporting. Our study also did not assess the different HPV genotypes.

\section{Conclusion}

A high prevalence of HPV and CIN was observed among women who were HIV positive. This calls for active screening and treatment of this susceptible population to prevent the further development of cervical cancer among them. The HIV/AIDS/ ART outpatient clinics should include sensitization sessions, awareness programs, and routine cervical cancer screening for HIV-positive women to avoid the development of CIN and higher lesions and achieve the goal of global elimination of cervical cancer.

Source of Funding

None.

\section{Authors' Contribution}

S.A.P. had the initial idea and was responsible for the conduct of the study, and participated in its conception and design, monitoring, supervision, acquisition, and interpretation of the data and the provision of clinical 
services in the study. V.P. was responsible for monitoring, supervision, acquisition, and interpretation of the data. G. A.M. was responsible for the study design, conduct, monitoring and supervision of the study, acquisition, analysis, and interpretation of the data. K.V.A. participated in the conduct and monitoring of the study, acquisition, and interpretation of data. All authors were involved in drafting the manuscript and have read and approved the text as submitted to the journal.

S.A.P., as corresponding author, confirms that she had access to all data and had final responsibility for the decision to submit for publication.

\section{Conflict of Interest}

None declared.

\section{Acknowledgments}

We are grateful to medical social workers, Ms. Parishi Majmudar, Mr. Ashok Patil, and Ms. Bhakti Kabre for providing counseling to HIV-positive women. We are thankful to Mr. Suresh Raibhatanavar and Ms. Nicole Aguirre for helping in data retrieval and analysis. We also thank Ms. Rupa Sarwaiya and Ms. Darshana Rane for data entry.

\section{References}

1 World Health Organization. Human papillomavirus (HPV) and cervical cancer fact sheet. 2020

2 de Sanjosé S, Brotons M, Pavón MA. The natural history of human papillomavirus infection. Best Pract Res Clin Obstet Gynaecol 2018;47:2-13

3 International Agency for Research on Cancer. GLOBOCAN 2020: New Global Cancer Data. 2021

4 International Agency for Research on Cancer. GLOBOCAN India 2020. 2021

5 van Hamont D, Bekkers RL, Massuger LF, Melchers WJ. Detection, management, and follow-up of pre-malignant cervical lesions and the role for human papillomavirus. Rev Med Virol 2008;18 (02):117-132

6 National AIDS Control Organization \& ICMR-National Institute of Medical Statistics. India HIV Estimates 2019: Report. New DelhiNACO, Ministry of Health and Family Welfare, Government of India2020 Available at: UNAIDS_INDIA HIV ESTIMATES-2.indd (naco.gov.in). Accessed September 22, 2021

7 Whitham HK, Hawes SE, Chu H, et al. A comparison of the natural history of HPV infection and cervical abnormalities among HIV- positive and HIV-negative women in Senegal, Africa. Cancer Epidemiol Biomarkers Prev 2017;26(06):886-894

8 World Health Organization. WHO guideline for screening and treatment of cervical pre-cancer lesions for cervical cancer prevention. 2021

9 Taku O, Businge CB, Mdaka ML, et al. Human papillomavirus prevalence and risk factors among HIV-negative and HIV-positive women residing in rural Eastern Cape, South Africa. Int J Infect Dis 2020;95:176-182

10 Sarkar K, Pal R, Bal B, et al. Oncogenic HPV among HIV infected female population in West Bengal, India. BMC Infect Dis 2011; 11:72

11 Averbach SH, Gravitt PE, Nowak RG, et al. The association between cervical human papillomavirus infection and HIV acquisition among women in Zimbabwe. AIDS 2010;24(07):1035-1042

12 Chakravarty J, Chourasia A, Thakur M, Singh AK, Sundar S, Agrawal NR. Prevalence of human papillomavirus infection \& cervical abnormalities in HIV-positive women in eastern India. Indian J Med Res 2016;143(01):79-86

13 Nyasenu YT, Gbeasor-Komlanvi FA, Ehlan A, et al. Prevalence and distribution of human papillomavirus (HPV) genotypes among HIV infected women in Lomé, Togo. PLoS One 2019;14(02):e0212516

14 Teixeira MF, Sabidó M, Leturiondo AL, de Oliveira Ferreira C, Torres KL, Benzaken AS. High risk human papillomavirus prevalence and genotype distribution among women infected with HIV in Manaus, Amazonas. Virol J 2018;15(01):36

15 Sahasrabuddhe VV, Bhosale RA, Joshi SN, et al. Prevalence and predictors of colposcopic-histopathologically confirmed cervical intraepithelial neoplasia in HIV-infected women in India. PLoS One 2010;5(01):e8634

16 Bogale AL, Belay NB, Medhin G, Ali JH. Molecular epidemiology of human papillomavirus among HIV infected women in developing countries: systematic review and meta-analysis. Virol J 2020;17 (01):179

17 Patel P, Rose CE, Collins PY, et al; NIH HIV/NCD Project Disease Condition Technical Operating Group. Noncommunicable diseases among HIV-infected persons in low-income and middleincome countries: a systematic review and meta-analysis. AIDS 2018;32(1, suppl 1):S5-S20

18 Belayneh T, Mitiku H, Weldegebreal F. Precancerous cervical lesion and associated factors among HIV-infected women on ART in Amhara Regional State, Ethiopia: a hospital-based cross-sectional study. Int J Health Sci (Qassim) 2019; 13(03):4-9

19 Atashili J, Miller WC, Smith JS, et al. Age trends in the prevalence of cervical squamous intraepithelial lesions among HIV-positive women in Cameroon: a cross-sectional study. BMC Res Notes 2012;5:590

20 Daniel GO, Musa J, Akindigh TM, et al. Prevalence and predictors of precancerous cervical lesions among HIV-positive women in Jos, north-central Nigeria. Int J Gynaecol Obstet 2020;151(02):253-259 